\title{
Urbanization and carbon dioxide emissions in Singapore: evidence from the ARDL approach
}

\begin{abstract}
The main aim of this article is to examine empirically the impact of urbanization on carbon dioxide emissions in Singapore from 1970 to 2015. The autoregressive distributed lags (ARDL) approach is applied within the analysis. The main finding reveals a negative and significant impact of urbanization on carbon emissions in Singapore, which means that urban development in Singapore is not a barrier to the improvement of environmental quality. Thus, urbanization enhances environmental quality by reducing carbon emissions in the sample country. The result also highlighted that economic growth has a positive and significant impact on carbon emissions, which suggests that economic growth reduces environmental quality through its direct effect of increasing carbon emissions in the country. Despite the high level of urbanization in Singapore, which shows that $100 \%$ of the populace is living in the urban center, it does not lead to more environmental degradation. Hence, urbanization will not be considered an obstacle when initiating policies that will be used to reduce environmental degradation in the country. Policy makers should consider the country's level of economic growth instead of urbanization when formulating policies to reduce environmental degradation, due to its direct impact on increasing carbon dioxide emissions.
\end{abstract}

Keyword: Carbon emissions; Economic growth; Singapore; Trade openness; Urbanization 